\title{
Un nacionalista en apuros (El inconsistente separatismo de Ulises Moulines)
}

\author{
AURELIO ARTETA \\ Universidad del País Vasco
}

RESUMEN. El artículo pretende ofrecer una réplica detallada del «Manifiesto nacionalista» de Ulises Moulines (Isegoría, núm. 24, junio 2001). Entre las muchas debilidades de aquella defensa del nacionalismo étnico destaca la incomprensión del sentido de unos cuantos conflictos intranacionales. Pues, lejos de ser síntoma de la existencia de una nación sojuzgada (por ejemplo, la actual vasca), podrían ser más bien señal de lo contrario: de que en esa población no hay conciencia nacional suficiente para demandar la soberanía política y de que es el nacionalismo el interesado inductor del conflicto. Si la mini-teoria de etnias y naciones de Moulines se limita a reafirmar la radical indefinición de tales conceptos, tampoco su principio del Valor intrínseco de la pluralidad del Ser (infundado tanto en ética como en estética) aporta prueba alguna de un presunto derecho de las naciones a su independencia. Igual que se pasa por alto la más que dudosa compatibilidad entre nacionalismo étnico y democracia, se presupone que un Estado multinacional «las más de las veces» no puede funcionar. En suma, vuelta al viejo principio de las nacionalidades.

Como es de esperar que la condición de «filósofo de la ciencia»se apoye siempre en la previa y más general de sujeto político y moral, no seré yo quien regatee a Ulises Moulines su derecho a transgredir fron-
ABSTRACT. In this article I critically examine Ulises Moulines's «Nationalist Manifesto» (Isegoría, num. 24, June 2001). I argue that his defence of ethnic nationalism, amongst its many flaws, shows an unability to understand the significance of many intra-national conflicts. Instead of providing evidence of a nation's (i. e., the basque) oppression, those conflicts might well be a symptom of the opposite phenomenon within the population: namely, that in the absence of a national consciousness strong enough to require political sovereignty, the only engine behind the conflicts is the nationalist movement's self-interest. While Moulines's mini-theory of nations and ethnic groups merely asserts the radical ambiguity of those concepts, his Principle of the Intrinsic Value of the Plurality of Being (which is as unconvincing in ethics as in esthetics) does not provide any argument for a nation's right to independence. The difficult issue of how to make ethnic nationalism compatible with democracy is completely ignored by him; rather, it is presupposed that «more often than not» a multinational state simply will not work. At last, the Manifesto boils down to just another re-enactment of the old Principle of Nationalities.

teras disciplinares y a sentar tesis de carácter ético-político acerca del nacionalismo. Le reprocho, eso sí, que sean disparatadas y por ello indignas (26) ${ }^{1}$ no ya de un ilustre pensador, sino de un ciudadano dotado de 
alguna conciencia crítica. De ahí que no deje de extrañar que quien se excusa por ser tan sólo «un pobre filósofo de la ciencia» (44), y no de la política, se comporte en esta materia con un desenfado que le envidiaría el más curtido de los especialistas. Llama no menos la atención que ese al que aquejan deficiencias como las que se verán enseguida esté presto a reprochar una y otra vez las presuntas debilidades que al parecer afectan a los demás: ya sea el «notable déficit conceptual y metodológico» en el tratamiento del nacionalismo por parte de las disciplinas teóricas (26), o bien la «gran indigencia teórica» (31) o el lamentable «nivel de indigencia conceptual» en su discusión ordinaria (47). De momento no parece preciso dar gracias al cielo por dignarse depararnos al fin la buena nueva del profesor Moulines.

Nuestro hombre carece de reparos en cruzar asimismo las fronteras geográficas lejanas, pero se anda con mayor tiento en acercarse a las más próximas. Alude, pues, a los nacionalismos que asolaron la ex Yugoslavia, apela con soltura lo mismo al caso irlandés, judío o gitano que a bávaros y neozelandeses, menciona de pasada a los de la Unión Sudafricana y Burundi, y así a varios más. Sólo que, pese a su nacionalidad española, a su estrecha relación con Cataluña y a escribir en una revista de pensamiento político-moral afincada en España, se cuida muy mucho de esbozar siquiera una mirada a los nacionalismos de nuestra tierra. En especial, al vasco, seguramente el problema político español más grave - por ser el único sangrientodel presente. Nunca sabremos si se trata de una respetable medida de cautela elemental (si bien un tanto exagerada, a la

- vista de la distancia que separa Munich de San Sebastián) o bien de un hábil subterfugio para evitar todo cotejo entre sus apacibles reflexiones y un nacionalismo cuyos dichos y hechos, mientras invocan argumentos como los suyos, instalan a diario la barbarie. Intenciones y resultados al margen, trataré de probar que buena parte de las tesis del profesor Moulines consiste precisamente en sus notables inconsistencias. Y si esto se da en una figura justamente prestigiosa del pensamiento lógico-científico, pueden figurarse el grado de coherencia argumental del que acostumbra hacer gala el nacionalista ordinario.

\section{Hay amores que matan}

Ciertos modos que adopta el amor a la patria, por ejemplo. Contra lo que el autor parece suponer (26), son pocos los estudiosos de las emociones que las encuadren entre los fenómenos irracionales. Al contrario, el cognitivismo dominante en este campo da por sentado que afectos y sentimientos responden más bien a creencias, juicios y percepciones de sus sujetos ${ }^{2}$. Otra cosa es el grado de razonabilidad de tales creencias, que es lo que importa para decidir acerca del valor de verdad o de bondad de las emociones en cuestión.

Sea como fuere, no parece que el amor a la patria sea la raíz psicológica suficiente del nacionalismo, porque se puede ser patriota sin ser nacionalista $\mathrm{y}$, mucho menos, nacionalista de carácter etnicista. Ahí está el republicanismo antiguo, moderno o contemporáneo para probarlo ${ }^{3}$. Dígase más bien que el sentimiento nacionalista es «el estado de enojo que suscita la violación del principio [nacionalista] o el de satisfacción que acompaña a su realización», siendo tal principio político el que sostiene que «debe haber congruencia entre la unidad nacional y la política» ${ }^{4}$. De suerte que ni hay que considerar la emoción nacional como natural e inevitable (26), ni el antinacionalista se erige siempre en su adversario (27), sino sólo cuando equivale a ese «sentimiento de filiación hacia un objeto que el individuo siente que lo trasciende, algo que percibe a la vez como un objeto externo a sí mismo 
y componente fundamental de su propia identidad» (26). Para probarlo, aún rebrota de vez en cuando aquí y allá el nacionalsocialismo, que también es un nacionalismo.

En esos casos, ciertamente, el crítico del nacionalismo lo mira como «un grave desorden psíquico» $(27)^{5}$ y no habrá ciudadano digno de tal nombre que se engañe acerca de sus peligros manifiestos y no procure reprimirlo o superarlo. Para empezar, porque bajo aquella fórmula el patriotismo sería una especie más de fanatismo colectivo, una emoción de naturaleza religiosa que contradice frontalmente el sentimiento y afiliación democráticos..., aunque no trajera otros efectos nocivos. Por si ello fuera poco, porque semejante sentimiento busca un enemigo real o imaginario en que descargarse $\mathrm{y}$, en consecuencia, será tanto más peligroso cuanto más fervor patriótico se incube en esta nación o en aquélla. Y, finalmente (éste es uno de los más clamorosos vacíos en la reflexión de $\mathrm{Mou}$ lines), porque sus riesgos aumentan asimismo a tenor de las resistencias que encuentra entre los no nacionalistas de su propia y pretendida nación...

Lo que aquí se llama negacionismo podría entonces, contra lo que Moulines dice (27) y sin incurrir en absurdo alguno, afirmar la existencia de una nación y a la vez tildar ese sentimiento del amor a la patria como «producto de una ilusión o quizá incluso de una alucinación» (30). Exista o no nación en algún sentido verificable, por lo pronto, lo ilusorio suele ser la historia que el patriota se inventa, las graves afrentas de las que cree (o lo simula) haber sido objeto y los incuestionables derechos individuales y colectivos (a fin de cuentas, a la soberanía política) que se atribuye. Así las cosas, nada tiene de extraño que el negacionista - si es un ciudadano demócrata y por la cuenta que le traetenga por un deber moral $(y$, en primer término, político) curar a los pacientes de tal ilusión o reprimirla. Pero no, como a
Moulines le interesa dejar caer al descuido, «a cualquier precio» (27) o «por todos los medios disponibles» (30), sino con las debidas cautelas y a través de los cauces de un Estado de Derecho.

Claro que el éxito de tal exigencia moral supone algo que nuestro hombre descuida dilucidar: a saber, que los afectos no constituyen fenómenos ineluctables y dados para siempre; que somos responsables de nuestros sentimientos, en la medida en que, siendo razonables, resultan asimismo educables. Añádase a ello que el empeño de transformar ese afecto patriótico no proviene de algún capricho. Tampoco se trata, por cierto, de que aquel nacionalismo entrañe una mera ilusión o «grotesca» alucinación, como el gusto por la caricatura del adversario le lleva a Moulines a calificar. Es sencillamente que sentimiento $\tan$ excluyente puede -o tiene queimpulsar una conducta pública injusta $y$, como la experiencia muestra de sobra, violenta y hasta mortífera con el resto de los connacionales primero y con los extranacionales después. Al menos a poco de cierto que contenga esa citada definición de Rustow de nación como «un grupo cuyos miembros colocan la lealtad al grupo como totalidad por encima de cualesquiera otras lealtades contrapuestas» (31), incluidas las ciudadanas y democráticas. O sea, el viejo right or wrong, my country. Así que aquella pasión frustrada no sólo puede volver a los nacionalistas «locos de amor» (34); es que con alguna desgraciada frecuencia los convierte en criminales. Lo mismo les hace capaces de «sacrificar la propia vida» (27) que de arrebatar sin pena o con fruición las ajenas.

De etnias, naciones y otros entes vagarosos

Pero antes habrá que ponerse de acuerdo sobre el significado de nación y el Manifiesto pasa revista a un variado elenco de definiciones (31 y ss.) para desecharlas una 
tras otra a causa de sus notorias insuficiencias. El propio Juan Villoro, autor de «el tratado más sistemático y ponderado» que nuestro profesor confiesa conocer sobre el tema, propone cuatro condiciones necesarias de pertenencia a una nación que aquí se desestiman enseguida como problemáticas (32-33). De manera tal que habría que tildar al concepto de marras como «indefinible» (39) y todo indica que nuestro autor está a punto de incurrir en ese negacionismo que ha merecido hasta entonces sus acerbas críticas.

Pero Moulines no se arredra y nos ofrece su propia «mini-teoría de etnias y naciones» $(40$ y ss.) que, la verdad sea dicha, no progresa un gran trecho en su conocimiento. Tales etnias no sólo no ofrecen un factor determinante que pueda tenerse por específico, sino que cuentan con unos límites espacio-temporales «borrosos» o «difusos» y originan manifestaciones fenoménicas «imprecisas». Aceptada la imposibilidad de fijar unos criterios tanto de delimitación de una etnia como de pertenencia a ella, sus rasgos esenciales deben quedar abiertos y ni siquiera la lengua es un componente seguro o exclusivo. Así las cosas, parece un tanto osado afirmar, no obstante, que las etnias son entidades «genidénticas» o que en buena medida rigen la marcha de la Humanidad o, en fin, que las naciones son unas etnias políticamente autoconscientes. Son cuestiones que me rebasan a mí y los límites de mi réplica. Los que saben de esto apuntan que la noción de etnia fue un invento de la antropología colonial inglesa para clasificar a sociedades diferentes de las nuestras que se les aparecian como carentes de instituciones políticas... Pero no sólo resulta - llamativa la extraordinaria vaguedad con la que ciertas teorías sociales se sirven de tales palabras y «la sorprendente facilidad con la que lo admiten» ${ }^{6}$. Más chocante todavía es la aparente inconsciencia con la que - pese a ello- aderezan tales palabras para su uso nacionalista (o les inyec- tan su contenido doctrinal), como hace nuestro profesor al extraer las «consecuencias deontológicas» de su teoría (44).

Pues sucede que «aún no sabemos bien a bien lo que es una nación»; de acuerdo, pero ello no obsta para que exactamente dos líneas más abajo sepamos de ella algo fundamental que Mill ya sabía: que «es característico de ellas que deseen disponer de un Estado propio, en tanto instrumento jurídico-político para defender su identidad nacional y desarrollarla» (33) ${ }^{7}$. En definitiva, no va a tardarse mucho en pasar de eso que a lo sumo sería un hecho (y ya se ve que harto confuso), la etnia, a la nación de los nacionalistas y a su seguro derecho. Explicar la nación, por la vía de su naturalización, será justificar el nacionalismo.

a) Lo primero es el nacionalismo. Ya hemos visto que uno puede profesar de negacionista sin obligarse a negar la nación y negando nada más que el nacionalismo (o la nación de los nacionalistas). De igual forma, se puede ser contranacionalista sin ser contranacional, o sea, sin ver en las naciones «realidades nefastas» (30) y detectando el carácter nefasto más bien del nacionalismo. Pues su argumento suele ser justamente el contrario del que Moulines le achaca: no que «las naciones son la causa, o al menos una condición necesaria, para el surgimiento del nacionalismo» ' (ibid.), sino al revés. Para mayor exactitud, que la etnia puede preceder al nacionalismo igual que puede prescindir enteramente de él; pero que siempre es el nacionalismo ese movimiento o doctrina que infunde a una población su conciencia nacional y, por consiguiente, que la anima a dotarse de la voluntad de alcanzar algún reconocimiento político o incluso rango estatal (38). Según eso (y es postura adoptada por buena parte de los estudiosos), el nacionalismo antecede a la nación y al Estado nacional, hasta el punto de construir a una y a otro. 
No otra cosa es lo que, en aparente inconsecuencia, mantiene poco después nuestro autor. Pues resulta que «una nación es una etnia que ha tomado conciencia política de sí misma» (38), que «las naciones son (...), etnias que disponen de un programa político (...) de preservación y desarrollo de su propia identidad» (43). Todo apunta a que aquella conciencia nacional, ese «proyecto común» (32), este programa político, puesto que no son preexistentes, han de ser precisamente productos del nacionalismo. $Y$ en efecto lo son, según reconoce sin ambages Moulines: «Cuando este esfuerzo por preservar su existencia (...) se traduce en un programa de acción política (...), tenemos que la etnia en cuestión se ha transformado en una nación, y al programa concomitante lo podemos calificar de "nacionalista"» (45). En resumidas cuentas, lo posterior es la nación y el Estado, y lo primero el nacionalismo, que es de lo que aquí toca hablar.

b) La nación del nacionalista. Pero al nacionalismo muñidor de naciones, según parece, le preceden todavía esas entidades naturales llamadas etnias. Esas entidades tan dudosas que hace poco parecían del todo reacias a ser conceptualmente captadas, no ofrecen ahora duda alguna acerca de su existencia.

Frente a la vieja epistemología positivista, para la que todo concepto científico debe estar referido a entes observables, Moulines (35 y ss.) postula la existencia de entidades determinadas sólo por medios puramente teóricos. Como los electrones en física, estas entidades teóricas no son detectables por los sentidos, pero constituyen los presupuestos para comprender ciertos fenómenos -que serán sus efectos-, éstos sí de carácter observable. Pues bien, «en la medida en que los electrones son reales, también lo son las naciones». Y antes aún, las etnias: «Las etnias... son cosas reales, que tienen una existencia propia» (44, cfr. 37).
Uno se pregunta si no valdría lo mismo abducir la existencia de Dios a partir de la constatación indubitable de los millones de creyentes en Él, bajo cualquiera de sus figuras y advocaciones, $o$ de los innegables efectos de todo género causados por las religiones o las iglesias ${ }^{8}$. Pero es que, además, la precisión que se nos ofrece no se limita a jugar un papel epistemológico, sino sobre todo otro de carácter normativo. Quiero decir que, en virtud de su propia naturaleza, la existencia teórica de las etnias y naciones se transmuta en una existencia práctica. Otro tanto ocurre con la presunción de la existencia divina, que no se contenta con su mero ser afirmada. Así que cuidado con las abstracciones. Hablar de electrones, de gramática profunda, de genes o de flujos de entropía es una cosa; hablar de etnias y naciones (o de mercado), otra. Entre tales conceptos se da aquella diferencia que Aristóteles establecía entre theoría y práxis, según la cual, si la primera trata de lo siempre igual y se dirige a su pura contemplación, la segunda tiene por objeto lo que puede ser de otra manera (o sea, lo deliberable y elegible) y persigue su transformación ${ }^{9}$. Nación es, en su uso ordinario y por el interés que suscita, un concepto normativo. Viniendo al caso, mientras la idea de electrones permite explicar ciertos fenómenos que de otro modo quedarían ignotos, el concepto de nación, además de explicar conductas individuales o colectivas, tiende a producirlas; esto es, ordena o propone unas acciones con respecto a tales naciones y desaconseja las contrarias. De ahí que los primeros, en tanto que denotan entidades no humanas, permanecen ajenos a cualquier juicio de valor; los segundos, en cambio, se refieren a grupos de hombres cuya acción libre exige ser moral y políticamente juzgada.

En todo caso, lo que no podrá dudarse es que para el nacionalismo [y se recordará que un propósito explícito de Moulines es «defender el nacionalismo» (30 y 26)] el uso normativo del concepto de nación es 
el exclusivo. Es el nacionalismo (como movimiento, pero antes aún como doctrina política) el que se encarga de definir la nación mediante unos pocos rasgos de inclusión y exclusión que previamente ha seleccionado y que a menudo están lejos de ser generales en la población de la que se predica ${ }^{10}$. Más todavía, es el nacionalismo el que proclama no sólo la existencia indubitable de las naciones y que el mundo está dividido entre ellas, sino también los derechos políticos de esas naciones... Para Moulines, el nacionalismo enuncia una «perogrullada moral» (47); para mí, ciertamente estamos ante una simpleza teórica, pero a menudo de supuestos inmorales y con efectos inciviles.

\section{El olvidado caso de los conflictos «intra-nacionales»}

De momento es cosa de ver cómo aquella anunciada defensa del nacionalismo se nutre de varios presupuestos ocultos y perfectamente falsables. Uno vendría a estipular que todos los nacionalismos arraigan en poblaciones formadas por una sola etnia $o$, tras el proceso nacionalista consiguiente, en una sola nación. Otro, que el programa nacionalista será «conscientemente apoyado por una parte significativa de la población» (45). Esto es ponerse las cosas demasiado fáciles... A nuestro autor ni se le ocurre pensar que buena parte de los nacionalismos étnicos -el vasco entre ellos- viven en y de las condiciones contrarias, o sea, en territorios de mestizaje étnico, larga historia de convivencia y faltos de una suficiente conciencia nacional. Si hubiera aceptado esta precariedad de : partida, tal vez entendería también su resultado necesario: que la exacerbación propia de esos nacionalismos no se debe a la injusticia y violencia con que son reprimidos, que eso hasta les fortalece a veces; se debe más bien a la violencia e injusticia con que los creyentes deben afirmar su hipotética nación y sus presuntos derechos frente a sus convecinos.

Pero los falsos prejuicios no han hecho más que empezar. El profesor Moulines sabe que «en ocasiones pueden surgir conflictos de intereses legítimos», pero el caso típico que propone es el que tiene lugar entre naciones (48). Aunque también conoce conflictos entre los individuos, ni se le pasa por la cabeza que puedan tener precisamente por pretexto su pertenencia o no a una determinada nación o su aquiescencia al proyecto nacionalista de «construcción nacional» y su pretensión de soberanía política. Ni como hipótesis de trabajo llega a considerar que los intereses de los no nacionalistas puedan ser tanto o más legítimos que los de sus adversarios. Si contemplara esa hipótesis, seguiría constatando el gran número de «conflictos políticos y militares en el mundo», así como su predominante carácter de intra-estatales..., pero no por fuerza inter-nacionales en el sentido genuino de «enfrentamientos entre dos o más naciones en el seno de un mismo Estado» (34).

Pues podría ocurrir que fueran más bien enfrentamientos entre una etnia minoritaria (o, al menos, políticamente no mayoritaria) y el resto de la población que, o no se considera parte de esa etnia o que, siéndolo, no comparte, sin embargo, el propósito de independencia política que el nacionalista le asigna. Dicho de otro modo, el contraste entre la homogénea nación ideal y la heterogénea nación real incita al nacionalismo a resolverlo a base de excluir de la auténtica comunidad nacional a los desprovistos de los rasgos adecuados. Surge así una «población sobrante» alrededor de la cual, y dentro de las propias fronteras políticas, se levanta una nueva e insidiosa frontera interior ${ }^{11}$ Se trata de una población que en su mayor parte se siente tanto de su etnia particular como de la propia del Estado en que se inserta, que vive una situación que se ha dado en llamar de «doble pertenencia» o 
de «identidades compartidas» ${ }^{12}$. En un sentido ajustado, pues, cabe tildar a tales conflictos de intra-nacionales. Se dan en el seno de un Estado, pero antes todavía en una comunidad menor de ese Estado; en esta probable coyuntura el combate nacionalista no se libra primero contra el Estado mismo, sino contra la propia comunidad en que habita y a la que pretende «liberar» sin su consentimiento mayoritario.

$\mathrm{O}$, lo que es igual, tan abundantes conflictos y «otros muchos procesos socioculturales» no son necesariamente síntomas de la «constitución de una nación o de diferenciación de naciones». Esto no siempre es así, por «evidente» y «trivial» (34) que se le antoje al profesor Moulines. En múltiples casos, y en proporciones variables, pueden ser síntomas inequívocos de que no existe tal nación o por lo menos no en el grado de conciencia y voluntad suficientes para emprender un proceso de soberanía política, porque los más se sienten también o sólo miembros de la nación más general en que desde hace siglos unos y otros conviven. La eventual violencia no brota ex abundantia de unas reivindicaciones nacionales contrariadas. Además de señal de las carencias opuestas, la violencia más bien se presenta como el único modo de superarlas o colmarlas. El terrorismo bajo cualquiera de sus formas sangrientas sería el medio para crear, incrementar o avivar esa conciencia nacional insuficiente $\mathrm{y}$, en último término, justificar su proyecto unilateral de secesión política. «Para dar realidad a la Causa y hacer verdadero a su dios, nada mejor que una buena carga de hechos, y de entre los hechos, nada mejor que una buena carga de muertes. Tal es iel principio. Y ciertamente imucho ha matado Euskadi para que pueda dudarse ya de su existencia!» ${ }^{13}$.

Todo lo contrario, pues, de lo que nuestro autor concluye del llamado argumento abductivo $(35,41)$. No siempre es la existencia indiscutible de naciones lo que per- mite dar cuenta de una serie de fenómenos políticos o culturales significativos, sino exactamente al revés: ciertos fenómenos que parecen responder a la existencia de naciones revelan más bien el propósito injusto (por parcial y contra la mayoría) de constituirlas a cualquier precio. Demuestran sin duda la presencia de algún nacionalismo, pero no de una indiscutible nación. Verbigracia, ciertas políticas lingüísticas no buscan sólo preservar o promover una lengua minoritaria; mediante un aparato legal de dudosa legitimidad (que regula desde la inmersión lingüística en una lengua que no es la materna ni la usual de la inmensa mayoría a la pura y simple invención léxica, de la innecesaria señalización vial o de rótulos hasta la recuperada o fabulosa toponimia de tiempos pretéritos), lo que buscan es forjar esa pregonada diferencia nacional que, a su vez, legitime la reivindicación soberanista. Cuando la lengua originaria se ha perdido o está en trance de perderse, en efecto, los nacionalistas hacen «esfuerzos sobrehumanos por "revivirla"» (42). Tan por encima de la voluntad de los sujetos afectados los hacen, con tal desprecio de sus derechos y del uso común de los hablantes, que tales esfuerzos bien podrían calificarse de inhumanos. Y es que, como la nación no existe aún como nación, habrá primero que edificarla; $y$, luego, esta «construcción nacionaly será el soporte y la palanca de la anhëláda construcción estatal.

\section{El culpable es el Estado}

Según el Manifiesto de marras (los prejuicios prosiguen), en los conflictos nacionalistas la culpa viene casi siempre de fuera y cae por lo común del lado del adversario estatal, según se echa de ver en las dos situaciones-tipo que considera.

Supóngase con Stuart Mill que sea característica de la nación el deseo de disponer de un Estado propio con vistas a 
defender y desarrollar su identidad (33), aunque ya se hizo notar que esa identidad, al menos como algo suficientemente definido o compartido, puede no pasar de un sueño o un desideratum sin fundamento mayoritario. Tampoco se justifica - y estamos ante una muestra de falacia naturalista- por qué de tal hecho ha de deducirse un derecho. Pero todo esto son cuestiones menores. Importa sólo resaltar que, cuando no logran convertirse por fin en Estados, es «generalmente debido a coacciones externas» (ibid.). Si antes que a indebidas coacciones externas se debieran a legítimas dificultades internas (como que la población misma se halle dividida sobre el particular), al parecer es pregunta capciosa o desdeñable. Si tales coacciones - estatales o internacionales- se justificaran acaso como garantía de los derechos de aquella parte de la población que sufre el acoso nacionalista..., eso ni se toca. Mejor dicho, ambas cuestiones carecen de sentido, porque nuestro autor da por supuesto - como aún se verá- que la pretensión independentista siempre es legítima $\mathrm{y}$, cuanto se le oponga, ilegítimo.

Pasemos de su independencia como Estado-nación a la autonomía política de una nación dentro de un Estado-multinacional. Dado que estamos ante una cuestión referida a la praxis, cuesta entender cómo, siendo esa solución autonomista «sin duda un arreglo ideal», pueda funcionar casi siempre bastante mal, "por no decir que no funciona en absoluto» (45). Perplejidades aparte, ¿cuál es la razón última de tal fracaso? Muy sencillo: que «en la inmensa mayoría de los casos» los Estados multinacionales reales no están constituidos por el consenso de las etnias que los componen, «sino por la voluntad, muchas veces extremadamente violenta, de una sola etnia predominante. En una palabra, se trata de Estados-nación hegemónicos» (46). Así las cosas, y si esta salida resulta «las más de las veces» tan nefasta, se diría que la lógica y la ética al unísono piden acogerse directamente a la fórmula anterior, o sea, a la plena soberanía, y no perder el tiempo en soluciones así de inviables...

A no dudar, hay sobrados ejemplos en el mundo susceptibles de ilustrar esta tesis. Sería asimismo verificable que muchos Estados nacionales proceden de la conquista de unas etnias por otras en tiempos pasados. Lo habitual, sin embargo, es que en los actuales no subsista ya una conciencia étnica $\tan$ resentida y, aunque así fuera, toca preguntarse si está justificada una «acción afirmativa» o de «discriminación positiva» que pretendiera reparar un crimen remoto por otro probable crimen presente... Sea como fuere, el autor no vacila en atribuir toda la responsabilidad de las tensiones propias del Estado multinacional a los presuntos abusos de la etnia hegemónica. Nunca a las insaciables pretensiones de las etnias supuestamente dominadas; a sus injustas discriminaciones respecto de sus propios conciudadanos, a los agravios cometidos contra otras etnias autónomas menos privilegiadas, a sus permanentes chantajes al Estado y así hasta el infinito. La España de hoy, un Estado multinacional y, por el grado de autonomía de que gozan sus etnias, de hecho cuasi-federal, sabe mucho de todo esto.

La violencia comprensible... ¿por merecida?

Ya anticipamos que la nación es como un ser humano: vive y sufre como él, se emociona como él $\mathrm{y}$, claro está, goza también de derechos que no deben ser contrariados. «Cuando a un individuo se le cortan las posibilidades de desarrollo de un modo que considera injusto o arbitrario, no hay por qué extrañarse si se enoja y reacciona con violencia. Lo mismo pasa con las naciones [cursiva mía], cuyo desarrollo es percibido por muchos de sus miembros también como condición de posibilidad de su propio desarrollo individual o el de fami- 
liares y amigos» (34). ¿Y entonces? Saquemos la consecuencia que este arriesgado pensador no se atreve a pronunciar en voz alta.

Más que aquel amor a la patria en que quería condensarse la absorbente pasión nacionalista, el disgusto y la ira incubados por el incumplimiento del principio político del nacionalismo - como era de temer- desemboca con mucha probabilidad en la violencia; lo que es más, incluso se diría que en una violencia justa. Lástima que su justificación no traspasa los límites de un subjetivismo o relativismo impropios de asunto así de dramático. Pues bastaría que muchos perciban que su propio desarrollo personal o familiar está coartado, porque asimismo lo perciben efecto de lo que perciben un propósito planeado de reprimir el desarrollo de eso que ellos perciben como su nación..., para que esos «muchos» (en nombre de su nación oprimida) reaccionen con violencia y nadie tuviera que sorprenderse por ello. De la descripción a la encubierta legitimación: ¿o no se viene cuando menos a insinuar que, siendo esa violencia merecida, nadie tendría tampoco derecho a defenderse de ella o a reprimirla? El profesor Moulines, como era de prever, no desciende a despejar incógnitas tan insignificantes.

\section{La diversidad como di-versíón ( $y$, si me apuran, divertimento)}

Él se conforma con vocear el principio ético-ontológico del Valor Intrínseco de la Pluralidad del Ser: «es algo bueno, que hay que preservar, o hasta fomentar en la medida de lo posible, el que haya muchas cosas de muy diversos tipos en el universo» (44). De donde se seguiría, así nos cuenta, el corolario de que «la destrucción de una entidad sólo está justificada para evitar un daño considerable o para promover un bien de tipo muy superior» (ibid.). Y, por si no fuera del todo per- suasivo (al autor le parece de nuevo algo «éticamente evidente»), aún se añadirá el argumento estético de que «es más bello o atractivo un mundo en el que haya muchas cosas de muy diverso tipo» que otro más aburrido compuesto de pocas cosas y pocos tipos (ibid.)

Pues ni lo uno ni lo otro. Ignoro si es verdad necesaria que el universo sea ontológicamente tanto más rico cuanto más diverso, que es cosa que dejo a los teóricos del mejor de los universos posibles. Sea de ello lo que fuere, me temo que de ahí no saldría ninguna estimación teórica ni directiva práctica para el mundo humano o de los valores. En lo que se refiere a nosotros, tal es nuestra semejanza básica que ya el mero subrayado de la diferencia se vuelve sospechoso: «... mientras no se diga en todo el mundo, en todas las lenguas de esta tierra, la verdad indiscutible de que todos los seres humanos se parecen entre sí más de lo que se diferencian, considero un pecado dar a conocer las diferencias entre los distintos pueblos antes que sus semejanzas y su igualdad...» ${ }^{14}$.

Más aún: no es verdad apodíctica que una humanidad más diversa, tan sólo por ser más diversa, sea mejor y más bella ni, en consecuencia, que sea éticamente y estéticamente más valioso preservar y hasta fomentar aquella diversidad. $\measuredangle O$ es que hay que preferir por principio la disparidad a la coincidencia, la desemejanza al parecido o el desacuerdo y el conflicto al acuerdo? El todo no es bueno porque se componga de muchas partes, sino porque sus partes son por sí mismas buenas o contribuyen al bien del conjunto. Una receta culinaria no es mejor tan sólo porque aumente el número de sus ingredientes, sino porque produce un sabor o un rendimiento proteínico apreciables, asî como tampoco el valor de una obra de arte reside en la variedad de sus elementos, sino en su armonía, mesura, ritmo o equilibrio. De igual modo, la excelencia del mundo de los hombres no radica simplemente en la 
multiplicidad de sus grupos, proyectos, creencias, conductas o instituciones, ni su pobreza moral estriba en que tales grupos, creencias, etc., disminuyan o rebajen las diferencias entre sí. De aplicar tal principio al individuo humano, su previsto enriquecimiento mediante la diversidad haría de él un perpetuum mobile, lo mismo de gustos $\mathrm{u}$ opiniones que de actitudes y modos de vida: su rica identidad consistiría en no ser nunca idéntico consigo mismo. Identidad nacional e identidad individual, sean ellas lo que fueren, se disolverían a cada instante.

Aquel principio funda más bien la tesis capital del multiculturalismo y otros torpes relativismos de nuestros días: que las cosas (o conductas o culturas) no son valiosas por lo que como tales valgan, sino nada más que porque son varias o distintas entre sí. De suerte que (y dicho sea de paso), según aquella doctrina ya no se trata de establecer diferencias de valor, sencillamente porque el valor único, y por lo general supremo, está en la mera variedad y diferencia. Con una sola salvedad: que lo excelente a fuer de diferente cause un daño considerable o impida la promoción de un bien muy superior, aunque ni aquel daño ni este bien merezcan el esfuerzo por definirlos. Una vez hecha esta vagarosa excepción, pues, digamos adiós a los criterios y juicios normativos, rechácese toda jerarquía moral, bienvenido sea el relativismo cultural y ético, abracemos el nihilismo con sus pompas y sus obras.

«La diversidad, en sí misma, no tiene ninguna connotación moral positiva» ${ }^{15}$, empero. En caso contrario, no sólo cualquier comportamiento - menos los extremosamente abominables- debería ser

i permitido, sino que nuestro relativista tendría que admitir como valiosa la peculiaridad del etnocentrismo o del imperialismo mismos, que no dejan de ser acendradas formas de diversidad cultural. Para Moulines habría que preservar y fomentar esas diferencias étnicas que a nosotros se nos antojan aberrantes, con tal de que resulten inmejorables a los ojos de sus miembros; es decir, de que éstos las tengan por «condición de posibilidad de su propio desarrollo individual» o de los suyos (34). En cuanto quede subsumida bajo el principio del valor de la pluralidad del ser, la cuestión de quién, cómo y con arreglo a qué criterio político-moral puede decidir acerca del bien o del mal causados o del bien superior impedido por el cultivo de aquella peculiaridad queda sin resolver. Ya no hay razones para sostener que sólo serán legítimas las formas de vida que permitan a todos la satisfacción de sus necesidades primarias.

De manera que esa «regla general» según la cual «hay que dejar a cada existente que siga su vía» (44) sería aceptable según y cómo. Se aceptará cuando este dejar vivir (que comprenderá también el dejar morir de muerte natural), un supuesto que excluye el destruir esas variadas entidades, no equivalga por sistema a preservarlas o fomentarlas. Significa simplemente juzgar que algo - una práctica, una creencia, una institución - no es lo bastante valioso como para conservarlo a toda costa, sobre todo a costa de necesidades más amplias, graves y perentorias; y concluir, por tanto, que no concurre deber alguno individual ni colectivo que nos obligue a su conservación ni menos aún a su fomento. Verbigracia, una lengua prácticamente desaparecida o en trance de desaparición. Lo malo es que aquella regla general, que distingue entre el resto de seres vivos y los seres humanos a fin de consentir la subordinación de los segundos a los primeros en caso de necesidad..., no repara tanto en la distinción de status entre entidades humanas individuales y las colectivas, así como en la conveniencia de someter éstas a aquéllas. «La idea de que las formas de vida tienen derecho a sobrevivir (...) - recuerda Gauthier - es un recién llegado al escenario moral; es también una idea totalmente equivocada. Son los individuos los que cuentan; las formas de vida 
importan sólo como expresión y sustento de la individualidad humana» ${ }^{16}$. El lector de Moulines hallará, por el contrario (46 y ss.), más surtidas referencias a la identidad y a los supuestos derechos de la nación que a los reales de los individuos.

\section{Los derechos según el fantasma (25)}

Pero nos hemos internado ya, no sólo en el mundo humano o cultural, sino en el espacio político en particular, allí donde la validez de aquel principio ético-ontológico de la pluralidad deja aún más que desear. El razonamiento se limita a aducir que en el mundo hay etnias y que las etnias tienen derecho a alcanzar una cierta soberanía política (tal como se plasma en ese programa político de acción que es el nacionalismo). Es el aquí denominado «principio de autodeterminación de las etnias» (39).

Al parecer, las etnias «están en su perfecto derecho» (45) y hasta en la «obligación» (48) de preservar así su identidad y existencia al menos por tres razones: a) según se dijo más atrás (34), porque sería la condición indispensable para asegurar la propia identidad y el desarrollo de los individuos; b) como se añadirá al final, porque los entes colectivos gozan de idénticos derechos y deberes que los entes individuales (48), y $c$ ) entremedio, porque ese derecho sería una plasmación inmediata del principio del valor intrínseco de la pluralidad, dado que «es bueno (o al menos más divertido) que haya (...) diversos tipos de grupos humanos...» (45). Miremos de cerca tales razones.

a) La primera es una tesis bien arriesgada a poco que se recuerden las dificultades que entrañaba determinar los requisitos que ha de cumplir una etnia y delimitar los factores de la pertenencia a ella. Que el desarrollo del grupo étnico sea condición del desarrollo de sus miembros no es decir nada mientras no se aporte más información con sentido. De un lado, dígasenos qué propiedades específicas de esa etnia son psicológica o moralmente tan relevantes para los individuos y el grupo como para requerir su salvaguarda y fomento a través de una parcial o total soberanía política... y por qué. ¿Por qué mi identidad personal depende de mi afiliación étnica (el «foco de identificación primario», al decir de Kymlicka ${ }^{17}$ ) más que de otras afiliaciones (familiares, religiosas o profesionales)? ¿Por qué es aquélla, y no alguna de éstas, la que al parecer exige el dominio sobre cierto espacio público? Más todavía, ¿́por qué admitir el argumento naturalista de que, supuesto que tal rasgo étnico sea constituyente de mi identidad, brota la consecuencia normativa de protegerlo por vía estatal? Esa norma sólo puede provenir de una valoración acerca de ese rasgo, una valoración de naturaleza cambiante y que debería hacerse en común. Todo eso sin olvidar que podría darse el caso de una falsa atribución de tales rasgos o de la invención pura y simple de la propia etnia o nación, como requisito previo de la reclamación nacionalista. Así ocurre, por ejemplo, con las «comunidades imaginadas» o en lo que se ha llamado el «narcisismo de las pequeñas diferencias» ${ }^{18}$. Cuando se trata de etnias desaparecidas de «muerte natural» o incluso «asesinadas» (46), hay que suponer algún intento de artificial resurrección, encaminada a recuperar los rasgos que en el pasado quizá pudieron definirla y que ahora contribuyan a avalar un futuro soberano.

Del otro lado - y puesto que apenas hay ya comunidad política que no sea cultural e ideológicamente mestiza-, sería conveniente aclarar hasta qué punto lo que para ciertos miembros de esa comunidad constituye un sedicente requisito para su desarrollo personal o social pueda ser para los demás producto de una conciencia mítica, históricamente errónea y moralmente ilegítima que, además de no compartir, 
arrastraría consigo su discriminación social y su exclusión civil. O sea, que serviría para someter unas personas y grupos a otros, y a satisfacer las imaginarias necesidades de entes de ficción a costa de las necesidades reales de individuos de carne y hueso. En estos y otros supuestos, más regulares de lo que Moulines da en imaginar, no habría que permitir que unos grupos humanos (entre otros, ni que decir tiene, los etnonacionalistas) «nos hagan la vida imposible a los demás» (45).

Se trata, según toda apariencia, de un argumento emotivista, incapaz de justificar por qué individuos que no experimentan la misma emoción han de adecuarse a directrices emanadas de impulsos afectivos ajenos. Al fin y al cabo, hay que distinguir entre el hecho necesario de que los individuos se perciban a sí mismos a través de su experiencia con múltiples hechos sociales, entre ellos su cultura, y los efectos políticos que los nacionalistas extraen de algunas de tales formas de autopercepción, que en modo alguno son necesarios. «Quienes hemos decidido no ser nacionalistas también nos sentimos unidos de un modo muy estrecho a nuestra cultura. Sin embargo, las consecuencias políticas que derivamos de ese sentimiento son muy distintas...» ${ }^{19}$. Lo que no hacemos es fundar en ese sentimiento ni el ámbito nuclear de la ciudadanía ni la legitimidad del poder que en él se ejerce..., como reza la doctrina central del nacionalismo. $\mathrm{O}$, lo que es igual, ni hacemos de la necesidad natural virtud ni convertimos el azar en destino político.

b) El empleo de esos conceptos por parte del nacionalista, naturalmente, no se anda con los remilgos de su uso científico. El nacionalismo, al dotar a la nación no

: ya sólo de existencia práctica, sino hasta de existencia parecida a la humana, va a entenderla como un verdadero Sujeto que domina sobre sus sujetos reales. He aquí el célebre misterio de la construcción especulativa (a través de los mecanismos de abstracción, inversión y subjetivación) que
Marx ya vislumbrara en la dialéctica hegeliana ${ }^{20}$ y que el nacionalismo cultiva con particular ahínco. Con qué penosos efectos, ya lo estamos comprobando.

«A nivel de colectividades humanas -advierte el profesor Moulines- ocurre aquí exactamente lo mismo que a nivel de los individuos mismos» (48), a saber, que la nación tiene el derecho y el deber de preservar su identidad. Pero, por más que nuestro autor se empeñe en humanizar y hasta personificar a las naciones, no parece que colectividades e individuos sean ni puedan ser exactamente lo mismo. Las colectividades no tienen una vida, un destino o una voluntad al margen y por encima de los individuos que las forman. En consonancia, tampoco disfruta de unos derechos ni le pesan unos deberes ajenos, anteriores y superiores a los de sus sujetos individuales. Estamos ante una nueva especie de enajenación o autodespojo de los atributos de los sujetos para construir así un fetiche (según la doctrina clásica, Dios, Estado, Dinero o Capital; en este caso, la Nación) ante el que los individuos deben postrarse $\mathrm{Y}$ como este Pueblo escogido - por mor de su abstracta naturaleza - no puede manifestar su voluntad por sí misma, lo hacen en su nombre quienes se autoerigen en sus profetas, intérpretes y sacerdotes; es decir, los nacionalistas.

c) Vengamos al último fundamento de esta legitimidad fantasmal. Ya se ha visto que aquel mentado principio del valor de la pluralidad no era ontológica, ni moral, ni estéticamente aceptable con validez universal. Tampoco vale para la política, donde representa el colmo de la incongruencia. Al margen de consideraciones democráticas, mejor se acoplaría con aquel principio un régimen político asentado en la diversidad etnocultural que otro que albergara una sola etnia. $Y$ es que la presunta ganancia en valor de una mayor heterogeneidad o pluralidad de Estados quedaría en entredicho por la homogeneidad étnica reinante en el seno de cada uno de 
ellos. Al nacionalismo ya no le es preciso aducir específicas razones políticas. Ahora, y en virtud de razones ontológicas, éticas y estéticas más generales, todas las etnias deben ser naciones en trance de auparse a Estados y todos debemos ser nacionalistas. Llevado a su extremo, por lo demás, mal se comprende el afán de otorgar carta de naturaleza política a todo lo diverso haya de detenerse en las etnias o naciones sin descender a las más variadas todavía entidades menores. Puestos a ello, y descartado el individuo en tanto que no mantiene relaciones civiles consigo mismo, ¿por qué no llegar a cada una de las familias humanas y proclamar su soberanía?

Lo gracioso, si no fuera trágico, es que el propio nacionalista tiene que pecar mortalmente y el primero contra este principio que pregona. Como observa Rodríguez Abascal en comentario de Gellner, «el nacionalismo no aumenta la diversidad cultural, sino que cuando desea influir en ella de algún modo es siempre para reducirla» ${ }^{21}$. El nacionalismo culturalista pretende un mapa cultural estático, no dinámico. Ya sea en su fase militante o en la triunfante, no descansa hasta homogeneizar su territorio a base de aplicar a todos los nacionales su plantilla. Ni fomenta la riqueza de prácticas culturales, sino que las discrimina con descaro a su favor; ni respeta, pongamos por caso, las variedades dialectales de su «lengua propia», sino que las elimina con vistas a su unidad lingüística que quiere ser luego política.

Pero es que, además, sólo una versión arcangélica de aquel principio puede proclamar que la pluralidad de etnias o naciones sea, si no directamente buena y bella, cuando menos inocua. Nunca han faltado déspotas iluminados que se hayan propuesto la eliminación del mundo de ciertas etnias so pretexto de que su mera existencia resultaba «causa de graves prejuicios para la Humanidad» (44). Ello no obsta para que la experiencia política más elemental enseñe que la pluralidad de etnias y naciones contiene una amenaza latente o manifiesta, que no hay etnia o nación que para afirmarse no se incline a negar a las vecinas; en suma, que en punto a las relaciones inter-nacionales vivimos aún en un estado de naturaleza. En realidad, una de las principales razones contra el nacionalismo es la imposibilidad del triunfo simultáneo y en perfecta armonía de todos los nacionalismos No son tan fáciles de conjurar aquellos conflictos de intereses supuestamente legítimos: «El nacionalismo plantea sus reivindicaciones como un juego de suma cero, y el solapamiento de varios nacionalismos sobre un mismo lugar sólo puede traer consigo un conflicto continuo e inacabable» ${ }^{22}$. Ockam lo habría tenido claro: Non sunt multiplicanda entia sine necessitate. Sólo un encantador wishful thinking puede entonces permitirse decir lo de Moulines: «El programa nacionalista por el que aquí se aboga no conlleva en absoluto el programa de una actitud agresiva de una nación hacia otra» (47). He ahí un nacionalismo de diseño o propio de la comunión de los santos.

\section{Por no hacer distingos}

Es de agradecer que nuestro autor, tal vez movido de un celo didáctico excesivo, nos enseñe a no confundir los conceptos de nación y de Estado (33) o entre el nacionalismó defensivo y el ofensivo (47); lástima que pase por alto otras distinciones más oportunas. Verbigracia, una cosa es la pluralidad y otra el pluralismo. En lo que atañe a las naciones igual que a los puntos de vista, la pluralidad de unas y otros será inevitable, pero no por fuerza buena (a menos que el acuerdo o la unidad libres sean, como tales, incontestablemente malos), ya sea por su relación con la justicia o con la verdad. Como no se trata de una pluralidad de mariposas o de minerales, sino de grupos humanos (sean étnicos o ideológicos), el riesgo de conflicto 
será mayor que sì reinara la unicidad de etnias o la unanimidad de pareceres. De modo que lo bueno sin discusión será el pluralismo como carácter de un régimen político que consagra como principios - con los límites que la naturaleza de la democracia impone - una sensata tolerancia y el respeto tanto de la máxima autonomía de sus «naciones» como de las libertades de los ciudadanos. Enunciemos, pues, el principio opuesto, el del valor intrínseco de la unidad o armonía del ser, y procuremos enraizarlo como el apoyo más firme de la política nacional e internacional. Lo que hay que preservar y hasta fomentar en lo posible es la unidad en la diversidad. Eso, naturalmente, siempre que un objetivo primordial de la política continúe siendo la paz interna y externa.

Convendría por eso distinguir también entre el pluralismo hacia fuera, que se demanda con pleno derecho del Estado en el que esa etnia o nación se encuadra, y el pluralismo hacia dentro de la propia comunidad política inferior, que a menudo se suprime o reprime contra todo derecho. Paradójicamente, cuanto más se acalle la pluralidad y disidencia internas, tanto mayor será la destemplanza con la que se exija la autonomía. $Y$ así, aquello que Moulines denuncia tan sólo como un fenómeno propio del Estado-nación hegemónico, «o sea, que promueven la hegemonía de una etnia sobre las demás» (46), sucede no menos dentro de las fronteras de ciertas partes de ese Estado dotados de autonomía política. De poco vale, pues, conceder que «no ha sido infrecuente que el nacionalismo haya derivado peligrosamente hacia el hegemonismo» (48), como enseguida se reduzca éste a los descomunales y sangrientos proyectos imperialistas de los Hitler, Mussolini o Milosevic.

De manera más franca o más larvada, ciertos grupos étnicos pretende subyugar a otras etnias «en nombre de una supuesta superioridad racial, cultural, económica o del tipo que sea» (47). Abundan los casos de minorías étnicas que han alcanzado su independencia sólo para emprender dentro de sus fronteras contra sus minorías las mismas persecuciones que ellos habían padecido ${ }^{23}$. Ni siquiera hay que esperar al día siguiente de la independencia para verificar este fenómeno. La obsesiva voluntad hegemonista del nacionalismo vasco en el seno de la variopinta (a resultas de más de un siglo de emigración laboral), compleja y plural (como consecuencia de procesos modernizadores) población de la Comunidad Autónoma Vasca sería por desgracia paradigmático. Para revindicar su superioridad, al arranque del siglo XXI y en este próspero rincón del planeta no hay reparo en fundarla incluso en decimonónicas medidas craniométricas y peculiaridades sanguíneas. Así que, con lo poco que costaría probar cómo ciertos nacionalismos en el propio país derivan hacia tendencias hegemonistas, «que siempre es correcto contrarrestar», no es fácil asumir por qué sacrosanta razón «siempre es correcto defender» el nacionalismo (48, cursiva mía).

A lo mejor fuera bueno acudir asimismo a una distinción subyacente a lo largo de esta réplica y que separa al llamado nacionalismo político del conocido como étnico. Mientras el primero florece en los Estados formados y arraigados a lo largo de siglos, el segundo es la ideología que impulsa a los que hoy aspiran a conquistar un status político soberano por secesión de los anteriores. A ambos les acechan las temibles tentaciones del nacionalismo, pero salta a la vista que por lo común aquél es de carácter más incluyente que éste. $\mathrm{Al}$ menos en el ámbito occidental, y bien que mal, el primer género ha asimilado el espíritu y los métodos democráticos, mientras el segundo - aunque se cubra con ese manto de moda - invoca sin pudor justificaciones opuestas, esto es, predemocráticas cuando no abiertamente antidemocráticas. Uno diría que el profesor Moulines, al reflexionar de modo principal sobre el naciona- 
lismo étnico, se desentiende del todo de la clave última para decidir sobre la legitimidad de su fundamento y de sus aspiraciones: a saber, la más que incierta relación entre este tipo de nacionalismo y el principio de la democracia. Ya sabemos que ésta no predetermina el ámbito territorial en que ha de instaurarse, pero, a la hora de cuestionarlo, exige desde luego justificaciones acordes con sus presupuestos últimos.

Porque en un régimen democrático no sólo importan los procedimientos formales de representación y decisión. Ellos son requisitos imprescindibles, ciertamente, para conocer la voluntad real de los ciudadanos de una nación, y ya sólo con eso tal vez se vendrían abajo muchas de las reivindicaciones nacionalistas de nuestras sociedades plurales. Pero la democracia es mucho más: es un principio de organización política enfrentado al que postula el nacionalismo étnico. Uno y otro se oponen respectivamente entre sí como la comunidad de adscripción a la comunidad de pertenencia o de sangre, los sujetos singulares al sujeto colectivo, la igualdad de derechos como ciudadanos al privilegio de los distintos como miembros de una etnia, la razón política a la fe religiosa... Por eso los «conflictos de intereses legítimos» entre naciones (o entre una nación y el Estado al que cuestiona) deben esclarecer antes que nada, en efecto, si son legítimos (48); y eso no puede resolverse sólo ni primordialmente «a través de negociaciones y compromisos», porque la democracia no es un mercado, sino a través de la argumentación ${ }^{24}$. Craso error el de suponer que «el verdadero enemigo del nacionalismo es el hegemonismo» (ibid.). El enemigo genuino del nacionalismo (étnico) es el principio de ciudadanía, o sea, el principio democrático en su versión republicana.

Era de esperar que nuestro autor aceptara sin problema alguno ser etiquetado de «nacionalista» (32). Tal vez por eso, tras haber transitado a través de su artículo con la escandalizada sorpresa de moverse entre lo trivial y lo evidente $(34,44)$, se permite al final calificar a ese nacionalismo de «perogrullada moral» o «ético-política» (47). Un diagnóstico tan resolutivo no sólo condena poco menos que por necedad o malevolencia (por no entenderlo o no querer entenderlo) a quienes no lo profesamos. Incomparablemente más grave es el reproche que lanza sobre millones de hombres de haberse entregado al matadero o a la carnicería nada más que por pura desatención de lo que era obvio o empecinamiento contra un derecho innegable. Por lo que a él mismo respecta, de tal grado de evidencia disfruta en su percepción del nacionalismo..., que puede prescindir de ofrecer argumentos de peso que la sustenten.

\section{Fuera del Estado uninacional no hay salvación}

Si lo juzga verdad de Perogrullo, se comprende enseguida su falta de empeño suficiente en persuadirnos de "por qué hay que ser nacionalista» (44). Pero, un paso más, y al profesor Moulines hace falta apurarle muy poco para que una especie de estatolatría le lleve a comulgar incluso con el separatismo más rancio y descabellado.

Un apartado anterior mostró cómo la graduación entre el objetivo nacionalista de la autonomía y el de la independencia política se desvanece hasta quedar en nada. Mejor dicho, en la práctica se desprecia de tal modo el primero de ellos, que el nacionalista debe ahorrarse esa opción para encaminarse sin más dilaciones ni rodeos a la plena soberanía. Pues es el caso que ese arreglo o solución ideal resulta nada más que aparente, y la responsabilidad de que casi siempre «no funcione en absoluto» recae tan sólo en los Estados multinacionales, que se comportan en realidad como Estados-nación hegemónicos. 
En definitiva, al ser incapaces de «tratar en pie de igualdad a las naciones que lo componen» ${ }^{25}$, originan «situaciones de injusticia» ante las que un «imperativo ético-político» ordena abandonar aquel Estado para formar otro propio (45-46).

Concedido que la gran mayoría de los Estados europeos son Estados multiétnicos, el relato de ficción ético-política nos cuenta que «en muchos de ellos» sus diversas etnias gozan de tal autoconciencia política que en realidad merecen el estatuto de naciones (45); lo lamentable es que - con la honrosa salvedad de Finlandia y Suiza-, la tensión permanente entre esas etnias que lo componen puede conducir al conjunto estatal incluso al borde de la guerra civil (ibid.). Si hasta aquí ha comparecido una notoria exageración, la incoherencia no se hace esperar. Al parecer de Moulines, la razón del casi seguro fracaso de un Estado multinacional «no es de orden conceptual (...); es decir, no hay en sí nada erróneo en la idea de un Estado multinacional», sino de índole histórico-empírica: la tendencia hegemonista de una etnia sobre las otras (ibid.). Claro que, para mantener el hábito, nuestro lógico no hace ascos a chapotear en plena contradicción a lo largo de esas mismas líneas.

Basta con pasar revista a sus prejuicios manifiestos. Pues si al mismo tiempo nos recuerda con Mill que, conforme a su naturaleza, no hay nación que no aspire a un Estado propio (33); si sostiene a la vez que «el nacionalismo genuino sólo [cursiva mía] reclama el derecho a la existencia de una nación en pie de igualdad con otras naciones» (47), y eso, por cierto, al margen de su peso demográfico y de cualquier otra consideración (46, cursiva mía); y si aquel principio del valor de la pluralidad recomendaba como justo, bello y saludable la existencia de tantas naciones cuantas fuera posible sin cometer daño grave (44)..., las conclusiones son opuestas a las adelantadas. El nacionalista, animado por un irreprimible deseo, cuyo objeto es también un derecho innegable y bendecido nada menos que por un principio ético-ontológico, no parará (mejor dicho: no debe parar) hasta convertir a su nación en Estado independiente. No son, pues, «las razones que sean» las que propician la «incapacidad» del Estado multinacional para crear las estructuras político-jurídicas que permitan la convivencia igualitaria y pacífica de sus propias naciones, a fin de que cada una de ellas «se sienta, por así decir, a gusto en casa» $(46)^{26}$. No es, en primera instancia al menos, esa real o supuesta impotencia estatal la que en consecuencia justifica la secesión política nacional (ibid.). Tratemos de jugar limpio y sin engañar. Son la propia doctrina, la creencia, el programa, la acción y la meta del nacionalismo étnico las que conducen esencialmente a negar, acosar y por fuerza desequilibrar al Estado en que su hipotética nación se inserta y del que pugna por separarse. Pues su nación ha de ser tan soberana como esa otra que da nombre al Estado del que forma parte ${ }^{27}$. Y quien introduzca cualquier consideración — sea de equidad o de mera prudencia - que cuestione su designio será enemigo a batir..., y a batir incluso con legítima (o siquiera comprensible) violencia.

De modo que aquella dificultad de partida no era de carácter histórico-empírico, como se pretendía, sino estrictamente conceptual y sustantiva. A los ojos de Moulines, y según la propia naturaleza y el derecho de las naciones, la idea misma de Estado multinacional es una contradictio in terminis. Para ser inestable e inseguro, un Estado así no necesita que una etnia imponga su imperio sobre las demás; le basta con ser multinacional para ser con toda probabilidad desigualitario y abocado al conflicto político. Ya que no un «arreglo ideal», desde luego, hasta debería dudarse de que se trate de un second best. Un Estado multinacional, por mucha autonomía que permita a sus etnias, será a priori injus- 
to. No hay otra solución justa que el Estado uninacional.

[Era hora ya de traerlo a colación. Sírvase el desprevenido lector advertir algo que, si no es olvido impremeditado, raya en la deshonestidad intelectual. Hete aquí que nuestro autor reproduce el juicio de Stuart Mill según el cual es propio de las naciones el desear disponer de un Estado propio (33), por lo mismo que ues condición generalmente necesaria de las instituciones libres la de que los límites de los Estados deben coincidir o poco menos con los de las nacionalidades" ${ }^{28}$. Lo que el profesor Moulines sospechosamente pasa por alto es que, a renglón seguido, Mill añade al menos dos consideraciones que ponen sordina a ese principio general. El primer obstáculo, de carácter geográfico, es que en Europa hay naciones «de tal manera mezcladas, que no les es posible vivir bajo Gobiernos separados». El segundo, de naturaleza moral y social, es que la experiencia prueba que a una sociedad le es posible y hasta ventajoso (y cita, entre otros, el caso de los vasco-franceses) fundirse y absorberse en otra. Culmina así con otro principio no menos general que aquel de partida y que echa por tierra sin remisión la tesis el Manifiesto: «Todo lo que tienda a mezclar las nacionalidades, a fundir sus cualidades y sus caracteres particulares en una unión común, es un beneficio para la raza humana». No está bien (o es un error) invocar a un clásico en nuestra ayuda a sabiendas (o con ignorancia) de que nos la niega. A menos que también en este punto la diversidad sea divertida...]

Volvemos así al viejo principio de las nacionalidades y proclamamos entonces sin disimulo que cada oveja con su pareja y cada nación con su Estado. Desde el siglo XIX nunca ha faltado en toda doctrina nacionalista la idea de que «el único tipo de gobierno legítimo es el autogobierno nacional» ${ }^{29}$. Moulines la disfraza ahora bajo el rótulo del nacionalismo internacio- nalista, que no deja lugar a dudas: «toda nación tiene el derecho, y hasta la obligación, de hacer lo posible por preservar su identidad; y al mismo tiempo tiene la obligación de respetar las condiciones para que las otras naciones preserven la suya» (48). ¿Qué es la identidad de una nación? Nada que sepamos a ciencia abierta, pero algo que el nacionalismo descubre ya en toda etnia. ¿Qué es el mundo político? Un conjunto de naciones que, puesto que cuentan con pleno derecho a ser Estado, tienen todo el derecho a separarse de los Estados en los que hoy se integran.

Se diría que, de acuerdo con la distinción de A. Buchanan, nuestro autor se sitúa enfrente de las teorías que postulan un derecho plebiscitario a la secesión política por parte de cualquier porción territorial de un Estado y, por el contrario, más bien a favor de las que toman partido por un derecho sólo terapéutico. Es decir, igual que el derecho a la revolución, la independencia política de un grupo será legítima cuando se ofrece como último recurso para remediar graves injusticias perpetradas contra ese grupo por parte del Estado al que pertenece. Pronto se echa de ver, sin embargo, que la justificación de Moulines se encuadraría mejor entre las plebiscitarias. Pues aquellas injusticias legitimadoras de semejante derecho han de entenderse como «persistentes violaciones de los derechos humanos, incluyendo el derecho a participar en el gobierno democrático, y el despojo injusto del territorio en cuestión, en caso de que ese territorio fuera previamente un Estado legítimo o una porción de un Estado legítimo» ${ }^{30}$. De donde se concluye que, salvo acuerdo negociado o derecho constitucional reconocido, no existe un derecho a la secesión respecto de un Estado legítimo, esto es, democrático. La reflexión de Moulines, en cambio, seguiría el derrotero opuesto: siempre o casi siempre se comete injusticia contra toda nación que aún no disponga de su propio Estado, ella no necesita nin- 
gún pretexto particular para plantear ese derecho a la secesión y, por tanto, puede ejercerlo en cualquier momento.

$\mathrm{Y}$ aquí pax perpetua y después gloria. La pena es que esa paz sería, con toda probabilidad, imposible y, aquel principio, indeseable además de inaplicable. Hoy existen al menos 1.500 etnias y algo menos de 200 Estados. Pues bien, según una amplia muestra y con datos de 1989, la mayor parte de los Estados contienen varias etnias (es decir, no son Estados-nación) y la mayoría de las etnias se reparten entre varios Estados (de modo que no son naciones-Estado). Sólo un 17 por 100 de los Estados se ajustaban al ideal de la correspondencia biunívoca entre nación y Estado, lo mismo que sólo un 5 por 100 de las etnias han hecho real la ecuación entre Estado-nación y nación-Estado ${ }^{31}$. Así las cosas, o multiplicamos los Estados hasta que cada uno se asiente sobre su nación, $\mathrm{y}$ hacemos el mundo políticamente aún más inhabitable, o renunciamos a la idea de Estado-nación: «si deseamos crear Estados viables que no estén sometidos a tensiones separatistas o violencias sobre/contra minorías étnicas, no hay más alternativa que separar la lealtad y la pertenencia a un Estado de la identidad cultural», distinguir «entre fronteras políticas y fronteras culturales». En otras palabras, la presente democracia de la diversidad, y ya no de la homogeneidad, exige hoy por su propia supervivencia culminar la: secularización religiosa del Estado hasta hacerlo laico también en lo cultural...

A la moda de 1848 el Manifiesto del profesor Moulines acaba entonando esta consigna: «Naciones (humilladas y ofendidas) de todo el mundo: uníos (contra los Estados hegemónicos)» (49). Son los lemas contrarios precisamente los que hoy pide corear la justicia entre Estados y en el interior de los Estados: «Ciudadanos del mundo, si queréis conservar vuestro rango de sujetos políticos, uníos contra todo nacionalismo».

$$
\text { * * * }
$$

Hay situaciones en las que puede ser legítimo recurrir al argumento ad hominem, y creo que ésta sería una de ellas. Más aún, tan grave es la situación que renunciar a ese argumento por pruritos de elegancia personal o de pureza lógica equivale a engañar al lector. Algunos profesores de la Universidad del País Vasco hemos sido señalados por los terroristas de ETA y, a instancias de las autoridades policiales y académicas, hemos debido dejar las clases y tenemos el futuro en suspenso. Más que una «indigencia conceptual» en nuestros escritos, la causa indudable de las amenazas de muerte es el acierto teórico con el que hace ya muchos años venimos públicamente denunciando al nacionalismo vasco, las barbaridades criminales del llamado radical y las injustas insensateces del tenido por moderado. Tal vez sean otros, pues, los que deban atender esa llamada al «compromiso teórico y práctico de políticos e intelectuales», si es que quieren evitar «errores de apreciación, repulsivos cuando no trágicos» (48). No estoy seguro de que el propio autor de estas fórmulas haya sabido sortear unos errores que se resumirían mejor bajo el nombre de objetiva complicidad. Si vale como síntoma, y por lo que a mi Facultad respecta, los profesores que más han jaleado y jalean la gloriosa trayectoria del Movimiento Vasco de Liberación Nacional son también los que han creído hallar en las tesis de este Manifiesto el mejor refrendo (iincluso moral!) de su jaleo. Sería de agradecer que el profesor Moulines les desmintiera a ellos o me desmienta a mí. 


\section{NOTAS}

${ }^{1}$ Replico al reciente Manifiesto nacionalista (o hasta separatista, si me apuran)», Isegoría núm. 24 (junio de 2001), pp. 25-49. La cifra antre paréntesis remite a la página del artículo de $U$. Moulines en que figura lo que en mi propio texto reproduce o comenta.

2 Algunas muestras: A. Ortony y otros, La estructura cognitiva de las emociones, Madrid, Siglo XXI, 1996. O. Hansberg, La diversidad de las emociones, México, FCE, 1996. J. Elster, Alchemies of the Mind, Cambridge UP, 1999. C. Castilla del Pino, Teoría de los sentimientos, Barcelona, Tusquets, 2000.

${ }^{3}$ M. Viroli, Por amor a la patria, Madrid, Acento, 1997.

${ }^{4}$ E. Gellner, Naciones y nacionalismo, Madrid, Alianza, 1988, p. 13

5 «El nacionalismo, es decir, la autocontemplación y egolatría nacionales, es en todas partes una enfermedad mental peligrosa, capaz de desfigurar y afear los rasgos de una nación, igual que la vanidad y el egoísmo desfiguran y afean los rasgos de una persona.» J. Roth, El Anticristo (pp. 229-30)

6 Así se entiende que Max Weber aconseje «arrojar por la borda" tales conceptos de etnia y nación (Economia y Sociedad, México, FCE, 1979, p. 324) o que Gellner llegue a negar pura y simplemente la existencia de naciones (op. cit., p. 70). Me lo ha recordado $\mathrm{L}$ Rodríguez Abascal, Las fronteras del nacionalismo Madrid, Centro de Estudios Políticos y Constitucionales, 2000 , pp. 86-87. Aprovecho la ocasión para recomendar vivamente la lectura de este libro, a mi parecer el trabajo más completo sobre el tema que se haya escrito en español y en los últimos tiempos.

${ }_{7}$ Pero no nos perdamos tampoco la incongruencia de esta última tesis con la afirmación del párrafo anterior, según la cual «el concepto de nación no tiene nada que ver con el de Estado»...

8 Debo tan aclaratorịa objeción al profesor Félix Ovejero, de quien solicité sus observaciones a este trabajo.

- Etica nicomaquea III.

10 «Colectivismo abstracto» llamará L. Rodríguez Abascal (op. cit., pp. 181 y ss.) a este procedimiento.

11 L. Rodríguez Abascal, op. cit., p. 191

12 Cfr. A. Maalouf, Identidades asesinas, Madrid, Alianza, 2001.

${ }^{13}$ R. Sánchez Ferlosio, Escritos y artículos, I, Barcelona, Destino, 1992, p. 216

14 J. Roth, op. cit., p. 121

is E. Garzón Valdés, «Cinco confusiones acerca de la relevancia moral de la diversidad culturals, en Ins" tituciones suicidas, México, Paidós, 2000, p. 235. Merece ser leído el trabajo entero, del que tomo prestada alguna otra idea.

16 Morals by Agreement, Oxford, Clarendon Press, 1986, p. 288 [hay edición española]. Cit. en E. Garzón Valdés, op. cit., p. 208.
${ }^{17}$ Ciudadanía multicultural, Barcelona, Paidós, 1996, p. 129.

${ }_{18}$ Cfr. B. Anderson, Las comunidades imaginadas, México, FCE, 1997. M. Ignatieff, El honor del guerrero, Madrid, Taurus, 1999.

19 L. Rodríguez Abascal, op. cit., p. 275.

${ }^{20}$ K. Marx, La sagrada familia, cap. V, 2 y 6.

${ }_{21}$ L. Rodríguez Abascal, op. cit., pp. 377 y ss. Cfr.

E. Gellner, op. cit., pp. 81-82.

22 L. Rodríguez Abascal, op. cit, pp. 251-253.

23 A. Buchanan, «Democracy and Secession», en M. Moore, National Self-Determination and Secession, Oxford U. P., 1998, p. 14. Cfr., del mismo autor, Secession (Westview Press, Boulder, 1991), y «Theories of Secession» (Philosophy and Public Affairs, 26/1, 1997, pp. 30-61).

${ }_{24}^{24}$ Entre muchos, J. Elster, «Argumenter et négocier dans deux Assemblées Constituantes», Révue Française de Science Politique, 44 (1994), 2, pp. 187-256.

${ }^{25}$ A menudo ocurre exactamente lo contrario: el conflicto nace de que los nacionalismos respectivos no consienten que sus hipotéticas naciones sean tratadas por el Estado en pie de igualdad con el resto, sino con arreglo a privilegios de toda clase y bajo la amenaza de romper la unidad en caso contrario...

26 «... lo malo del nacionalismo no es el deseo de autodeterminación en sí, sino esa ilusión epistemoló gica de que nadie puede encontrarse en su casa ni sentirse comprendido si no es entre sus iguales absolutos. El error nacionalista no está en el deseo de mandar en casa, sino en creer que allí sólo merece vivir su propia gente» (M. Ignatieff, op. cit., p. 61). «En vez de decir: queremos ser seres humanos en todos los países del mundo, decían querer ser señores en su país» (J. Roth, op. cit., p. 66).

${ }^{27}$ Según J. Breuilly, una de las tres afirmaciones nucleares de la doctrina política del nacionalismo e que «la nación tiene que ser tan independiente como sea posible. Habitualmente, esto exige al menos la obtención de la soberanía política» (Nacionalismo y Estado, Barcelona, Pomares Corredor, 1990, p. 13 Tomado de L. Rodríguez Abascal, op. cit., p. 167, n. 5).

${ }^{28}$ Del gobiemo representativo, cap. XVI. Cito por la edición de Lucas Verdú para Madrid, Tecnos, 1965 pp. 330-31.

${ }^{29}$ E. Kedourie, Nacionalismo, Madrid, Centro de Estudios Constitucionales 1988, p. 1.

${ }^{30}$ A. Buchanan, op. cit., p. 25

${ }^{31}$ Son datos de G. P. Nielssen, «Sobre los conceptos de etnicidad, nación y Estadon, en A. Pérez-Agote (dir.) Sociologia del nacionalismo, Bilbao, Gobierno Vasco, 1989, pp. 193 y ss. Recogido por E. Lamo de Espinosa, «Lengua, Nación y Estado», Claves de Razón práctica, abril, 2002 (121), pp. 16-17. Las conclusiones que expongo a continuación son del propio Lamo de Espinosa. 